\title{
Relationship between the number of prenatal care visits and the occurrence of adverse perinatal outcomes
}

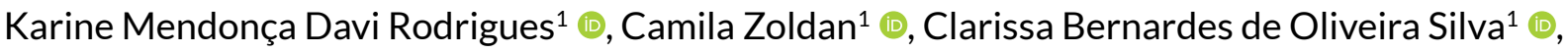 \\ Eduardo Félix Martins Santana² (1) Edward Araujo Júnior ${ }^{3 *}$ (1), Alberto Borges Peixoto ${ }^{1,4}$ (1)
}

\begin{abstract}
SUMMARY
OBJECTIVE: The objective of this study was to analyze the relationship between the number of prenatal care visits and the occurrence of adverse perinatal outcomes in an average city in the state of Minas Gerais, Brazil.

METHODS: This was a prospective and observational study. The variables analyzed were obtained through a questionnaire administered to postpartum women (between 1 and $48 \mathrm{~h}$ postpartum) and information contained in prenatal cards. The pregnant women were classified into three groups: Group I, $<3$ prenatal care visits; Group II, 3-5 prenatal care visits; and Group III, $\geq 6$ prenatal care visits.

RESULTS: Group I had a lower median weight ( 57.0 vs. 64.0 kg, p<0.001), body mass index (22.1 vs. $\left.24.3 \mathrm{~kg} / \mathrm{m}^{2}, \mathrm{p}<0.001\right)$, and weight gain (9.0 vs. $12 \mathrm{~kg}, \mathrm{p}=0.002)$ than Group III. The prevalence of admission to the neonatal intensive care unit (11.6 vs. 4.2\%, $\mathrm{p}=0.02)$ and the newborn mortality rate within the first $72 \mathrm{~h}$ of life ( $2.3 \mathrm{vs.} 0 \%, \mathrm{p}<0.001$ ) were higher in Group I than in Group III. Group II had a higher prevalence of admission to the adult intensive care unit ( 5.7 vs. $0.6 \%, p<0.001$ ) and a higher newborn mortality rate within the first $72 \mathrm{~h}$ of life $(1.6 \%$ vs. $0 \%, p<0.001)$ than Group III. CONCLUSIONS: Having $\geq 6$ prenatal care visits was associated with lower rates of admission to the neonatal and adult intensive care unit, as well as a lower newborn mortality rate within the first $72 \mathrm{~h}$ of life.
\end{abstract}

KEYWORDS: Prenatal care. Obstetric delivery. Pregnancy outcome.

\section{INTRODUCTION}

Prenatal care includes a set of actions aimed at reducing the risk and severity of maternal and fetal morbidity and mortality ${ }^{1}$. The Brazilian Ministry of Health recommends at least six prenatal care visits: one, two, and three prenatal visits in the first, second, and third trimesters of pregnancy, respectively. In addition, these services must be indicated on the prenatal cards of pregnant woman, as this monitoring is used to diagnose and treat preexisting diseases or diseases that may arise during pregnancy ${ }^{2}$.

Prenatal care can contribute to decrease adverse perinatal outcomes, especially in developing countries and socially disadvantaged populations ${ }^{3}$. A study conducted in a rural region of Rwanda reported that pregnant women who had only one prenatal care visit had higher rates of low birth weight and preterm delivery compared with those with $\geq 4$ visits ${ }^{4}$. A study conducted in Ethiopia showed that $\leq 4$ prenatal care visits was an independent predictor of adverse perinatal outcomes (i.e., stillbirths, fetal malformations, macrosomia, low Apgar scores $)^{5}$. Likewise, among pregnant women from the traditional
Bedouin community, lack of prenatal care was associated with adverse perinatal outcomes, and it was found to be an independent risk factor for preterm birth, low birth weight, and perinatal mortality ${ }^{6}$.

In contrast, adequate prenatal care has been related to lower rates of obstetric complications, such as the hypertensive syndromes associated with pregnancy ${ }^{7}$. Prenatal supplementation with folic acid and iron reduced the risk of obstetric complications (e.g., postpartum bleeding, premature rupture of membranes, and puerperal sepsis) in pregnant women in a rural area of $\mathrm{Nepal}^{8}$.

The objective of this study was to assess the association between the number of prenatal care visits and adverse perinatal outcomes in an average city in the state of Minas Gerais, Brazil.

\section{METHODS}

This was a prospective, observational, and descriptive study developed between August 2019 and July 2020 in the Department

\footnotetext{
${ }^{1}$ Universidade de Uberaba, Mario Palmério University Hospital, Gynecology and Obstetrics Service - Uberaba (MG), Brazil.

${ }^{2}$ Escola de Medicina Albert Einstein, Department of Maternal and Child - São Paulo (SP), Brazil.

${ }^{3}$ Universidade Federal de São Paulo, Paulista School of Medicine, Department of Obstetrics - São Paulo (SP), Brazil.

${ }^{4}$ Universidade Federal de Triângulo Mineiro, Department of Obstetrics and Gynecology - Uberaba (MG), Brazil.

*Corresponding author: araujojred@terra.com.br

Conflicts of interest: the authors declare there is no conflicts of interest. Funding: none.

Received on December 03, 2021. Accepted on December 05, 2021.
} 
of Obstetrics and Gynecology of Mário Palmério University Hospital, Uberaba, MG, Brazil. The study was approved by the Research Ethics Committee of the University of Uberaba (UNIUBE) under CAAE no. 96383118.7.0000.5145. Consent forms were signed by all participants who voluntarily agreed to participate.

The inclusion criteria were women undergoing vaginal delivery or cesarean section during the study period. The exclusion criteria were women who refused to participate in the study and who were unable to complete the data collection instrument due to their inability to understand it.

The relationship between the number of prenatal care visits and the occurrence of adverse perinatal outcomes was analyzed in patients from the public, supplementary, and private health care systems. The number of prenatal care visits was assessed by analyzing the prenatal cards of pregnant women.

Serology performance during the prenatal period was considered adequate when the patient underwent the following tests at least once or repeated them for every 3 months: HIV, syphilis (VDRL), toxoplasmosis IgM and IgG, rubella IgM and $\operatorname{IgG}$, cytomegalovirus (CMV) IgM and IgG, hepatitis B (HBsAg), and hepatitis C (anti-HCV).

Ultrasound evaluation during the prenatal period considered first-trimester ultrasound when performed between 6 and 13 weeks and 6 days, second-trimester ultrasound when performed between 20 and 24 weeks, and third-trimester ultrasound when performed between 28 and 40 weeks of pregnancy.

The evaluated variables were age; weight; smoking; alcoholism; use of illicit drugs; number of pregnancies; parity; type of health service; number of miscarriages; high-risk pregnancy; number of prenatal care visits; ultrasound examination in the first, second, and third trimesters; adequate serology (i.e., HIV, VDRL, toxoplasmosis, rubella, $\mathrm{HBsAg}$, anti-HCV, and CMV); type of delivery (vaginal, nonelective cesarean section, elective cesarean section, or forceps); birth weight; 1-min Apgar score $<7$; admission to the neonatal intensive care unit (ICU); admission to the adult ICU; need for oxygen; neonatal hypotonia; intracranial hemorrhage; intestinal bleeding; neonatal infection; neonatal birth trauma; newborn death within the first $72 \mathrm{~h}$ of life; surgical site dehiscence/infection; maternal death; and composite perinatal outcomes.

The data were entered into an Excel 2010 spreadsheet (Microsoft Corp., Redmond, WA, USA) and analyzed using the SPSS version 20.0 and Prisma GraphPad software version 7.0 (SPSS Inc., Chicago, IL, USA). Quantitative variables were analyzed using the normality test (i.e., Kolmogorov-Smirnov) and presented as mean and standard deviation (SD) values. Variables with a non-normal distribution were presented as median, minimum, and maximum values. Categorical variables were described as absolute frequencies and percentages and represented in tables. The difference between categorical variables and their proportions was analyzed using the chi-square test. The Kruskal-Wallis test was used to assess the difference between continuous variables. Dunn's post hoc test was used to compare pairs. The significance level for all the tests was set at $\mathrm{p}<0.05$.

\section{RESULTS}

During the study period, the data were obtained from 1,048 parturients. They were divided into three groups, as shown in Figure 1.

The following parameters had significant effects on the perinatal outcomes of the study group: age $(p=0.010)$,

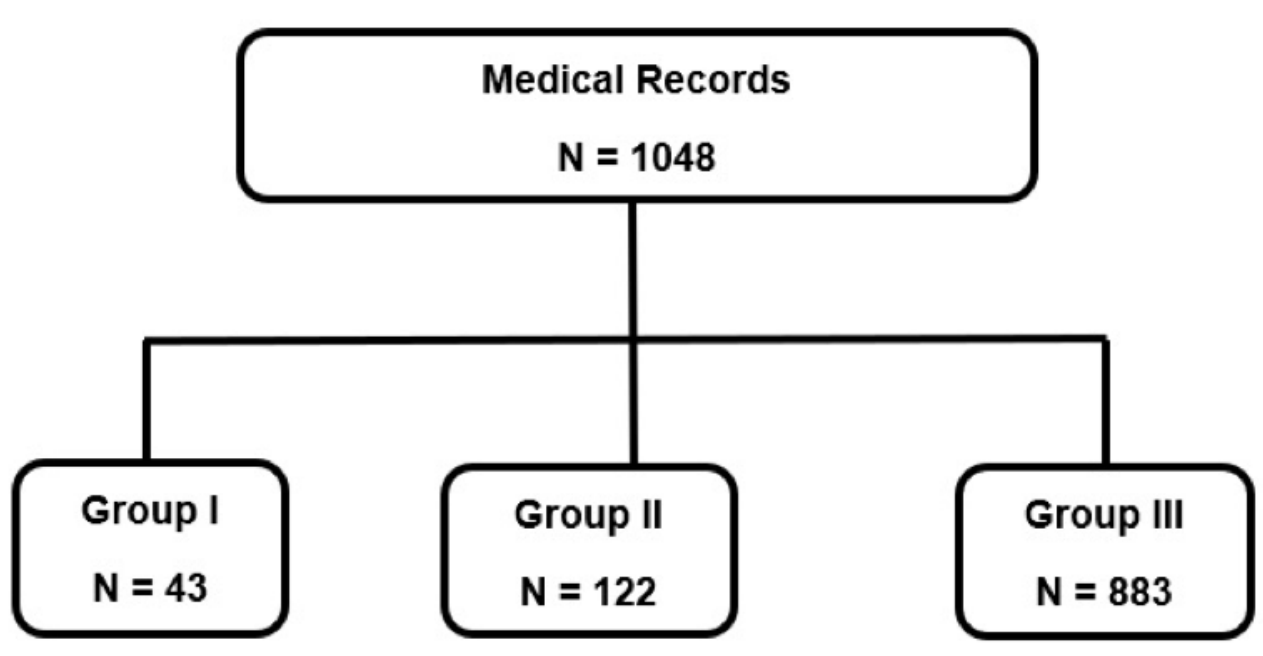

Figure 1. Flowchart of the cases included in the study. 
weight $(\mathrm{p}<0.001)$, body mass index (BMI) $(\mathrm{p}<0.001)$, number of pregnancies $(\mathrm{p}<0.001)$, parity $(\mathrm{p}<0.001)$, weight gain $(\mathrm{p}=0.002)$, gestational age at delivery $(\mathrm{p}=0.015)$, and birth weight $(\mathrm{p}=0.003)$ (Table 1$)$.

Comparison between pairs showed that Group I had a lower median maternal weight $(57.0$ vs. $64.0 \mathrm{~kg}, \mathrm{p}<0.001)$, BMI (22.1 vs. $\left.24.3 \mathrm{~kg} / \mathrm{m}^{2}, \mathrm{p}<0.001\right)$, and weight gain $(9.0$ vs. $12 \mathrm{~kg}, \mathrm{p}=0.002)$ than Group III. Group II had a lower median maternal age ( 23.0 vs. 26.0 years, $\mathrm{p}=0.010)$, maternal weight ( 58.5 vs. $64.0 \mathrm{~kg}, \mathrm{p}<0.001)$, BMI (22.7 vs. $24.3 \mathrm{~kg} / \mathrm{m}^{2}, \mathrm{p}<0.001$ ), gestational age at delivery (38.9 vs.
39.0 weeks, $\mathrm{p}=0.015)$, and birth weight $(3,078$ vs. $3,210 \mathrm{~g}$ $\mathrm{p}=0.003$ ) than Group III (Table 1).

There was a significant association between the perinatal outcomes of the study group and smoking $(\mathrm{p}<0.001)$, alcoholism $(\mathrm{p}=0.003)$, illicit drug use $(\mathrm{p}<0.001)$, type of health service $(\mathrm{p}<0.001)$, first-trimester ultrasound $(\mathrm{p}<0.001)$, second-trimester ultrasound $(\mathrm{p}<0.001)$, third-trimester ultrasound $(\mathrm{p}<0.001)$, adequate serology, presence of a companion during labor $(\mathrm{p}<0.001)$, and type of delivery $(\mathrm{p}<0.001)$ (Table 1$)$.

There was a significant association between the number of prenatal care visits of the study group and the prevalence of

Table 1. Clinical characteristics of the study population.

\begin{tabular}{|c|c|c|c|c|c|}
\hline & Group I (n=43) & Group II (n=122) & Group III (n=883) & $\chi^{2}$ & p \\
\hline Age (years) & $25.0(18-41)$ & $23.0(18-44)^{c}$ & $26.0(18-48)$ & 9.3 & $0.010^{+}$ \\
\hline Weight (kg) & $57.0(40-100)^{b}$ & $58.5(40.2-130)^{c}$ & $64.0(30-135)$ & 16.8 & $<0.001^{\dagger}$ \\
\hline Height (m) & $1.60(1.50-1.75)$ & $1.60(1.49-1.84)$ & $1.62(1.43-1.88)$ & 2.2 & $0.328^{+}$ \\
\hline BMI $\left(\mathrm{kg} / \mathrm{m}^{2}\right)$ & $22.1(16.4-39.1)^{b}$ & $22.7(14.7-50.1)^{c}$ & $24.3(12.3-47.8)$ & 17.9 & $<0.001^{\dagger}$ \\
\hline Smoking & $34.9 \%(15 / 43)^{a, b}$ & $9.8 \%(12 / 122)$ & $5.2 \%(46 / 883)$ & 57.5 & $<0.001^{s}$ \\
\hline Alcoholism & $27.9 \%(12 / 43)^{a, b}$ & $13.9 \%(17 / 122)^{c}$ & $11.0 \%(97 / 883)$ & 11.6 & 0.003 \\
\hline Illicit drug user & $14.0 \%(6 / 43)^{a, b}$ & $2.5 \%(3 / 122)$ & $0.6 \%(5 / 883)$ & 57.1 & $<0.001^{s}$ \\
\hline High-risk pregnancy & $65.1 \%(28 / 43)$ & $70.5 \%(86 / 122)$ & $64.6 \%(570 / 883)$ & 1.7 & 0.434 \\
\hline Number of pregnancies & $3(1-6)^{b}$ & $2(1-10)$ & $2(1-13)$ & 26.2 & $<0.001^{\dagger}$ \\
\hline Parity & $1(0-5)^{b}$ & $1(0-7)^{c}$ & $1(0-9)$ & 35.0 & $<0.001^{\dagger}$ \\
\hline Type of health service & & & & 29.5 & $<0.001^{s}$ \\
\hline Public & $95.3 \%(41 / 43)^{b}$ & $90.2 \%(110 / 122)^{c}$ & $71.7 \%(663 / 883)$ & & \\
\hline Insurance & $4.7 \%(2 / 43)^{b}$ & $9.0 \%(11 / 122)^{c}$ & $26.0 \%(230 / 883)$ & & \\
\hline Private & $0 \%(0 / 43)$ & $0.8 \%(1 / 122)$ & $2.3 \%(20 / 883)$ & & \\
\hline Weight gain (kg) & $9.0(-11 \text { to } 27)^{b}$ & $10.0(-23 \text { to } 51)^{c}$ & $12(-12.5$ to 34$)$ & 12.9 & $0.002^{\dagger}$ \\
\hline First-trimester US & $14.3 \%(6 / 42)^{a, b}$ & $30.6 \%(37 / 121)^{c}$ & $68.7 \%$ (594/865 & 108.0 & $<0.001^{s}$ \\
\hline Second-trimester US & $31.0 \%(13 / 42)^{a, b}$ & $74.4 \%(90 / 121)^{c}$ & $90.4 \%(782 / 865)$ & 134.0 & $<0.001^{s}$ \\
\hline Third-trimester US & $71.4 \%(30 / 42)^{b}$ & $75.2 \%(91 / 121)^{c}$ & $93.3 \%(807 / 865$ & 57.3 & $<0.001^{s}$ \\
\hline Adequate serologies & $42.9 \%(18 / 42)^{a, b}$ & $69.4 \%(84 / 121)^{c}$ & $89.9 \%(792 / 881)$ & 101.0 & $<0.001^{s}$ \\
\hline Gestational age at delivery (weeks) & $39.0(23.1-41.6)$ & $38.9(26.4-41.1)^{c}$ & $39.0(32.1-41.7)$ & 8.4 & $0.015^{\dagger}$ \\
\hline Companion during the labor & $86.0 \%(37 / 43)^{b}$ & $90.2 \%(110 / 122)^{c}$ & $97.3 \%(859 / 883)$ & 25.6 & $<0.001^{s}$ \\
\hline Type of delivery & & & & 35.1 & $<0.001^{s}$ \\
\hline Vaginal & $67.4 \%(29 / 43)^{b}$ & $63.1 \%(77 / 122)^{c}$ & $42.0 \%(371 / 883)$ & & \\
\hline Nonelective cesarean section & $20.9 \%(9 / 43)$ & $23.0 \%(28 / 122)$ & $24.7 \%(218 / 883)$ & & \\
\hline Elective cesarean section & $9.3 \%(4 / 43)^{b}$ & $13.1 \%(16 / 122)^{c}$ & $31.8 \%(281 / 883)$ & & \\
\hline Forceps & $2.3 \%(1 / 43)$ & $0.8 \%(1 / 122)$ & $1.5 \%(13 / 883)$ & & \\
\hline Birth weight (g) & $3,060(305-3,765)^{b}$ & $3,078(270-4,320)^{c}$ & $3,210(1,260-4,970)$ & 11.9 & $0.003^{+}$ \\
\hline 1-min Apgar score & $8(2-9)$ & $8(1-10)$ & $8(1-10)$ & 1.4 & $0.488^{+}$ \\
\hline 5-min Apgar score & $9(2-10)$ & $9(1-10)$ & $9(4-10)$ & 0.3 & $0.846^{\dagger}$ \\
\hline
\end{tabular}

BMI: body mass index; US: ultrasound. ${ }^{\top}$ Chi-square: percentage (absolute number/total number). ${ }^{\dagger}$ Kruskal-Wallis: median (minimum-maximum). ${ }^{\mathrm{a}} \mathrm{Dunn}{ }^{\mathrm{a}} \mathrm{s}$ posthoc test: group I vs. group II, p<0.05. 'Dunn's post-hoc test: group I vs. group III, $p<0.05$. 'Dunn's post-hoc test: group II vs. group III, $p<0.05$. 
Table 2. Comparison of the frequency of perinatal adverse outcomes between the three analyzed groups.

\begin{tabular}{|c|c|c|c|c|c|}
\hline & Group I ( $n=43)$ & Group II (n=122) & Group III (n=883) & $\chi^{2}$ & $\mathbf{p}$ \\
\hline 1-min Apgar score $<7$ & $14.6 \%(6 / 41)$ & $9.8 \%(12 / 122)$ & $6.7 \%(59 / 881)$ & 4.84 & 0.089 \\
\hline Neonatal ICU admission & $11.6 \%(5 / 43)^{a}$ & $8.2 \%(10 / 122)$ & $4.2 \%(37 / 883)$ & 7.87 & 0.02 \\
\hline Adult ICU admission & $2.3 \%(1 / 43)$ & $5.7 \%(7 / 122)^{b}$ & $0.6 \%(5 / 883)$ & 23.8 & $<0.001$ \\
\hline Oxygen need & $27.9 \%(12 / 43)$ & $26.2 \%(32 / 122)$ & $26.0 \%(230 / 883$ & 0.07 & 0.964 \\
\hline Neonatal hypotony & $14.0 \%(6 / 43)$ & $13.9 \%(17 / 122)$ & $13.9 \%(123 / 883)$ & 0.002 & 1 \\
\hline Intracranial hemorrhage & $0 \%(0 / 43)$ & $0.8 \%(1 / 122)$ & $0.2 \%(2 / 883)$ & 1.45 & 0.484 \\
\hline Intestinal bleeding & $0 \%(0 / 43)$ & $0 \%(0 / 122)$ & $0.1 \%(1 / 883)$ & 0.18 & 0.911 \\
\hline Neonatal infection & $0 \%(0 / 43)$ & $1.6 \%(2 / 122)$ & $1.0 \%(9 / 883)$ & 0.872 & 0.646 \\
\hline Neonatal birth trauma & $0 \%(0 / 43)$ & $0.8 \%(1 / 122)$ & $1.6 \%(14 / 883)$ & 1.1 & 0.578 \\
\hline Newborn death within the first $72 \mathrm{~h}$ & $2.3 \%(1 / 43)^{\mathrm{a}}$ & $1.6 \%(2 / 122)^{b}$ & $0 \%(0 / 883)$ & 16.6 & $<0.001$ \\
\hline Surgical site dehiscence/infection & $0 \%(0 / 43)$ & $0.8 \%(1 / 122)$ & $1.7 \%(15 / 883)$ & 2 & 0.536 \\
\hline Maternal death & $0 \%(0 / 43)$ & $0 \%(0 / 122)$ & $0 \%(0 / 883)$ & * & * \\
\hline Composite perinatal outcome & $60.5 \%(26 / 43)$ & $57.4 \%(70 / 122)$ & $51.8 \%(457 / 883)$ & 2.43 & 0.297 \\
\hline
\end{tabular}

ICU: intensive care unit. Chi-square: percentage (absolute number/total number). ${ }^{\mathrm{a} D u n n ' s ~ p o s t-h o c ~ t e s t: ~ g r o u p ~ I ~ v s . ~ g r o u p ~ I I I, ~ p<0.05 . ~}{ }^{\mathrm{b} D u n n ' s ~ p o s t-h o c ~ t e s t: ~}$ group II vs. group III, $p<0.05$.

admission to the neonatal ICU $(\mathrm{p}=0.02)$ and the adult ICU $(\mathrm{p}<0.001)$, as well as the newborn mortality rate within the first $72 \mathrm{~h}$ of life $(\mathrm{p}<0.001)$ (Table 2).

The prevalence of admission to the neonatal ICU (11.6 vs. $4.2 \%, \mathrm{p}=0.02)$ and the newborn mortality rate within the first $72 \mathrm{~h}$ of life ( 2.3 vs. $0 \%, \mathrm{p}<0.001)$ were higher in Group I than in Group III. Group II had a higher prevalence of admission to the adult ICU (5.7 vs. $0.6 \%, \mathrm{p}<0.001)$ and a higher mortality rate within the first $72 \mathrm{~h}$ of life ( $1.6 \%$ vs. $0 \%, \mathrm{p}<0.001)$ than Group III (Table 2).

\section{DISCUSSION}

The provision of adequate prenatal care is an important public health concern worldwide. Inadequate prenatal care is associated with unfavorable perinatal outcomes ${ }^{9}$. In Brazil, factors related to the quality of prenatal care were associated with a high chance of death in premature newborns ${ }^{10}$. Places with scarce resources and without adequate and qualified obstetric care have a higher probability of stillbirths ${ }^{11}$. However, as demonstrated by Líbera et al. ${ }^{12}$, for prenatal care assistance to effectively occur, it is crucial to involve pregnant women in issues related to their health.

Providing support for pregnant women and incorporating knowledge and skills through prenatal care can promote physical and mental health in minority women ${ }^{13}$. In this regard, the literature reports that geographic isolation, a major concern in
Brazil, still affects women's health care and is associated with worrisome perinatal data ${ }^{14}$.

In the present study, having $\geq 6$ prenatal care visits was associated with more favorable perinatal outcomes, such as lower rates of neonatal and adult ICU admissions and newborn mortality within the first $72 \mathrm{~h}$ of life. These findings corroborate with the study by Santos et al. ${ }^{15}$ that showed that having a minimum frequency of six prenatal care visits was a protective factor against low birth weight and prematurity.

The present study shows congruence with the new prenatal care model recommended by the World Health Organization (WHO), which raised the recommendation of the minimum number of prenatal care visits from 4 to 8 . Some studies showed that an increased number of visits are associated with a lower probability of stillbirths. This fact is explained by the better opportunity to detect and manage potential adverse outcomes. This change decreases perinatal deaths by up to 8 per 1,000 live births when compared to the minimum of four prenatal care visits ${ }^{16}$.

One of the limitations of the present study was that some of the data were collected from the prenatal cards of pregnant women, a document that always has a potential risk of adulteration, although this does not occur frequently. The relatively small sample size of the study patients may also have limited the accuracy of the results. The sample of the study patients may also represent a limiting element for obtaining even more 
accurate data. The disparity between the public and private health systems in Brazil could also have been a hindering element in adequate data analysis.

Adequate prenatal care is influenced by complex elements that involve the acceptance of pregnancy and even the recognition of the need for specialized care at this important moment in life. To reach the minimum number of visits, there is need to overcome barriers such as lack of knowledge and the demand for population awareness programs. The training of health professionals and their engagement in prenatal care are considered important factors that can affect perinatal outcomes ${ }^{17}$.

\section{CONCLUSION}

Having $\geq 6$ prenatal care visits was associated with lower rates of neonatal and adult ICU admission and newborn mortality within the first $72 \mathrm{~h}$ of life.

\section{AUTHORS' CONTRIBUTIONS}

ABP: Conceptualization, Project administration, Supervision. KMDR, CZ: Data curation. EFMS: Formal Analysis, Writing - original draft. CBOS: Investigation. EAJ: Methodology, Writing - review \& editing. CZ: Validation. KMDR, CZ, EFMS, EAJ, CBOS, ABP: Visualization.

\section{REFERENCES}

1. Chen XK, Wen SW, Yang Q, Walker MC. Adequacy of prenatal care and neonatal mortality in infants born to mothers with and without antenatal high-risk conditions. Aust N Z J Obstet Gynaecol. 2007;47(2):122-7. https://doi.org/10.1111/j.1479828X.2007.00697.x

2. Secretária do Estado de Saúde. Governo do Estado de Goiás. Pré-natal. Available from: https://www.saude.go.gov.br/ biblioteca/7637-pr\%C3\%A9-natal [Accessed 22nd November 2019.

3. Domingues RM, Leal Mdo C, Hartz ZM, Dias MA, Vettore MV. Access to and utilization of prenatal care services in the Unified Health System of the city of Rio de Janeiro, Brazil. Rev Bras Epidemiol. 2013;16(4):953-65. https://doi.org/10.1590/s1415$790 \times 2013000400015$

4. Akintije CS, Yorifuji T,Wada T, Mukakarake MG, Mutesa L, Yamamoto T. Antenatal care visits and adverse pregnancy outcomes at a hospital in rural western province, Rwanda. Acta Med Okayama. 2020;74(6):495-503. https://doi.org/10.18926/AMO/61209

5. Bililign Yimer N, Tenaw Z, Solomon K, Mulatu T. Inadequate prenatal visit and home delivery as determinants of perinatal outcomes: does parity matter? J Pregnancy. 2019;2019:9024258. https:// doi.org/10.1155/2019/9024258

6. Abu-GhanemS,Sheiner E,SherfM,Wiznitzer A, Sergienko R, ShohamVardi I. Lack of prenatal care in a traditional community: trends and perinatal outcomes. Arch Gynecol Obstet. 2012;285(5):1237-42. https://doi.org/10.1007/s00404-011-2153-x

7. Dutra GRSDF, Dutra LDC, Fonsêca GKSD, Nascimento Júnior MBD, Lucena EES. Prenatal care and hypertensive gestational syndromes: a systematic review. Rev Bras Ginecol Obstet. 2018:40(8):471-6. https://doi.org/10.1055/s-0038-1660526

8. Christian P, Khatry SK, LeClerq SC, Dali SM. Effects of prenatal micronutrient supplementation on complications of labor and delivery and puerperal morbidity in rural Nepal. Int J Gynaecol Obstet. 2009;106(1):3-7. https://doi.org/10.1016/j.ijgo.2009.03.040

9. Kapaya H, Mercer E, Boffey F, Jones G, Mitchell C, Anumba D. Deprivation and poor psychosocial support are key determinants of late antenatal presentation and poor fetal outcomes-a combined

retrospective and prospective study. BMC Pregnancy Childbirth. 2015;15:309. https://doi.org/10.1186/s12884-015-0753-3

10. Castro EC, Leite ÁJ, Almeida MF, Guinsburg R. Perinatal factors associated with early neonatal deaths in very low birth weight preterm infants in Northeast Brazil. BMC Pediatr. 2014;14:312. https://doi.org/10.1186/s12887-014-0312-5

11. McClure EM, Saleem S, Goudar SS, Moore JL, Garces A, Esamai F, et al. Stillbirth rates in low-middle income countries 20102013: a population-based, multi-country study from the Global Network. Reprod Health. 2015;12 Suppl 2(Suppl 2):S7. https:// doi.org/10.1186/1742-4755-12-S2-S7

12. Líbera BD, Saunders C, Santos MM, Rimes KA, Brito FR, Baião MR. [Evaluation of prenatal assistance in the point of view of puerperas and hetalth care professionals]. Cien Saude Colet. 2011;16(12):4855-64. https://doi.org/10.1590/s1413 81232011001300034

13. Gennaro S, Melnyk BM, O'Connor C, Gibeau AM, Nadel E. Improving prenatal care for minority women. MCN Am J Matern Child Nurs. 2016;41(3):147-53. https://doi.org/10.1097/ NMC.0000000000000227

14. Guimarães AS, Mantovani SAS, Oliart-Guzmán H, Martins AC, Filgueira-Júnior JA, Santos AP, et al. Prenatal care and childbirth assistance in Amazonian women before and after the Pacific Highway Construction (2003-2011): a cross-sectional study. BMC Womens Health. 2016;16:37. https://doi.org/10.1186/ s12905-016-0316-4

15. Santos MM, Baião MR, de Barros DC, Pinto Ade A, Pedrosa PL, Saunders C. [Pre-pregnancy nutritional status, maternal weight gain, prenatal care, and adverse perinatal outcomes among adolescent mothers]. Rev Bras Epidemiol. 2012;15(1):143-54. https://doi. org/10.1590/s1415-790×2012000100013

16. World Health Organization. WHO recommendations on antenatal care for a positive pregnancy experience. Geneva: World Health Organization;2016.Availablefrom:https://wnw.who.int/publications/i/ item/9789241549912 [Accessed 28th November 2016].

17. Jinga N, Mongwenyana C, Moolla A, Malete G, Onoya D. Reasons for late presentation for antenatal care, healthcare providers' perspective. BMC Health Serv Res. 2019;19(1):1016. https://doi. org/10.1186/s12913-019-4855-x 